\title{
A pilot study of a Medication Rationalization (MERA) intervention
}

\author{
Rachel Whitty BScPhm RPh, Sandra Porter BScPhm RPh, Kiran Battu BScPhm RPh, \\ Pranjal Bhatt PharmD, Ellen Koo MSc, Csilla Kalocsai PhD, Peter E. Wu MD MSc, \\ Kendra Delicaet MA, Isaac I. Bogoch MD MS, Robert Wu MD MSc, James Downar MD MHSc
}

\section{Abstract}

Background: Many seriously ill and frail inpatients receive potentially inappropriate or harmful medications and do not receive medications for symptoms of advanced illness. We developed and piloted an interprofessional Medication Rationalization (MERA) approach to deprescribing inappropriate medications and prescribing appropriate comfort medications.

Methods: We conducted a single-centre pilot study of inpatients at risk of 6-month mortality from advanced age or morbidity. The MERA team reviewed the patients' medications and made recommendations on the basis of guidelines. We measured end points for feasibility, acceptability, efficiency and effectiveness.

Results: We enrolled 61 of 115 (53\%) eligible patients with a mean age of 79.6 years (standard deviation [SD] 11.7 yr). Patients were taking an average of 11.5 (SD 5.2) medications before admission and had an average of 2.1 symptoms with greater than $6 / 10$ severity on the revised Edmonton Symptom Assessment System. The MERA team recommended 263 medication changes, of which $223(85 \%)$ were accepted by both the medical team and the patient. MERA team's recommendations resulted in the discontinuation of 162 medications (mean 3.1 per patient), dose changes for 48 medications (mean 0.9 per patient) and the addition of 13 medications (mean 0.2 per patient). Patients who received the MERA intervention stopped significantly more inappropriate medications than similar non-MERA comparison patients for whom data were collected retrospectively (3.1 v. 0.9 medications per patient, $p<0.01)$. The MERA approach was highly acceptable to patients and medical team members.

Interpretation: The MERA intervention is feasible, acceptable, efficient and possibly effective for changing medication use among seriously ill and frail elderly inpatients. Scalability and effectiveness may be improved through automation and integration with medication reconciliation programs.

$\mathrm{P}$ olypharmacy (the concomitant use of 5 or more medications) is present in more than half of the seriously ill and frail elderly 1,2 and is associated with medication errors, drug interactions, adverse drug reactions and nonadherence. ${ }^{3}$ Even as patients approach death, they are often prescribed a substantial number of non-comfort medications that are probably inappropriate and burdensome to patients and health care providers alike. ${ }^{4}$ At the same time, many dying patients are not given comfort medications (e.g., opioids), ${ }^{5}$ suggesting that the problem is not simply overtreatment but rather a mismatch between care and values. To promote deprescribing, various organizations have published lists and criteria for medications that are potentially inappropriate in older adults. ${ }^{6-8}$ Palliative care practitioners have also developed lists of medications with questionable benefit in patients with end-stage or terminal illnesses, ${ }^{4,9-12}$ such as pre- ventive medications with only long-term benefits. Yet there are many barriers to deprescribing ${ }^{3,13}$ and to providing comfort medications (e.g., opioids), ${ }^{14}$ even if these would appear to be rational choices for a patient nearing the end of life.

An effort to rationalize medications in the seriously ill and frail elderly, by deprescribing inappropriate medications and

Competing interests: James Downar has received a grant from Boehringer Ingelheim (Canada) and personal fees from Boehringer Ingelheim (Canada), Medtronic and Novartis for reasons unrelated to this study. No other competing interests were declared.

This article has been peer reviewed.

Correspondence to: James Downar, james.downar@utoronto.ca CMAJ Open 2018. DOI:10.9778/cmajo.20170134 
prescribing appropriate comfort medications, may simultaneously improve care and reduce costs. ${ }^{15,16}$ Deprescribing has been studied extensively in the general medical population, ${ }^{17-19}$ but there is little published research on this approach in patients nearing the end of life. ${ }^{20}$ Other medication-focused quality improvement initiatives have been broadly implemented, such as Antibiotic Stewardship ${ }^{21}$ and Medication Reconciliation, ${ }^{22}$ although they may not always improve patient care. ${ }^{23,24}$ In this study, we sought to develop and pilot a Medication Rationalization (MERA) team that would systematically rationalize medications for seriously ill and frail elderly patients admitted to a medical ward.

\section{Methods}

\section{Design}

We conducted a pilot study using a mixed-methods triangulation design (convergence model) in 2 populations: (1) patients and substitute decision-makers (SDMs) and (2) health care providers. We present the quantitative results of this study in this report.

\section{Participants}

\section{Patients}

The inclusion criteria were as follows: we enrolled seriously ill or frail elderly patients admitted to the general internal medicine ward who were at elevated risk of 6-month mortality or admission to the intensive care unit admission according to published criteria ${ }^{25}$ (Appendix 1, Supplement G available at www.cmajopen.ca/content/6/1/E87/suppl/DC1), or who were followed by the palliative care service. Exclusion criteria included refusal to consent to participate or refusal by the attending physician or delegate to enrol that particular patient. If the patient was not capable of providing consent, we approached their SDM to offer enrolment.

\section{Health care team members}

The inclusion criteria for the follow-up survey and qualitative components of the study were as follows: we offered enrolment to any consenting physician, medical trainee or pharmacist members of general internal medicine clinical teaching units (CTUs). Physician or pharmacist members of the MERA team were also offered participation in the qualitative component of the study. The exclusion criterion was refusal to consent to participate.

\section{Setting and duration}

The intervention was delivered on 2 of 6 general internal medicine CTUs at Toronto General Hospital between August and December 2015, and we screened the medical record of every patient admitted to those CTUs over that period to look for eligible patients. Screening took place during weekdays for any patient admitted in the previous 72 hours. We also collected medication data retrospectively on a comparison group consisting of consecutive eligible patients admitted concurrently to 2 CTUs where the MERA intervention was not delivered. A description of the units is provided in Appendix 1, Supplement A.

\section{Intervention}

The study coordinator screened the charts of newly admitted patients each day on the general internal medicine wards to identify patients who met the inclusion criteria, obtained informed consent to participate, collected demographic and clinical data (including the Clinical Frailty Score), administered baseline questionnaires to the patient or SDM and prepared a list of the patient's current medications for the MERA team. A MERA physician and pharmacist reviewed this information in the context of the patient's clinical history, symptoms and medications and made recommendations to stop, start or change doses of specific medications using a guideline-based algorithm (described in Appendix 1, Supplement B). Any disagreements about recommendations were resolved by consensus within the team. The study coordinator then arranged a meeting between the CTU attending physician (or delegate), the CTU clinical pharmacist, and a physician and/ or pharmacist from the MERA team to review the recommendations and discuss the potential need for additional symptomatic medication (e.g., opioids). If the admitting team disagreed with the rationale behind any MERA recommendation, the recommendation was dropped and not presented to the patient or family member.

A summary of the medication recommendations was then discussed with the patient or SDM by a member of the MERA team. Medication changes were only made with the consent of the patient or SDM. A written summary report of all medication changes made, including the rationale, was provided to the patient or SDM. Note that all patients admitted to our facility undergo both admission and discharge medication reconciliation; the discharge reconciliation does not always involve a pharmacist.

\section{Outcomes and analysis}

Our baseline data included demographic data and other pertinent information; the Patients' Attitudes Toward Deprescribing (PATD) questionnaire, a validated 15-item exploratory measure of acceptance of deprescribing; ${ }^{26}$ the Beliefs about Medicines Questionnaire (BMQ), a validated 17-item questionnaire assessing beliefs about the necessity, toxicity and overuse of medications ${ }^{27}$ (Appendix 1, Supplement C); and the revised Edmonton Symptom Assessment System ${ }^{28}$ (ESAS-r). We collected data on pilot outcomes to evaluate the feasibility, acceptability, time efficiency, and effect of MERA (justification in Appendix 1, Supplement D), and we analyzed medication use 3 months after discharge using the Ontario Drug Benefit (ODB) program database (which would have information for many medications taken by participants over age $65 \mathrm{yr}$ ). Our co-primary outcomes were the enrolment rate and the acceptability of the MERA intervention to patients/SDMs.

Data were analyzed descriptively for most outcomes. Demographic comparisons between the intervention and nonMERA comparison groups were made using a $t$ test for continuous variables and $\chi^{2}$ test for categorical variables. Numbers of 
medications prescribed, recommended discontinuations and accepted discontinuations were compared between nonMERA comparison and intervention groups using a MannWhitney $\mathrm{U}$ test as the data were nonparametric. Comparisons involving more than 2 categorical predictor variables were made using a Kruskal-Wallis analysis of variance. Multivariable linear regression was used to measure the association between demographic and baseline data and the number of medications discontinued.

\section{Ethics approval}

This study was approved by the University Health Network Research Ethics Board (No. 15-8840-A).

\section{Results}

We enrolled 61 of the 115 (53\%) eligible patients admitted during the study period (Figure 1). For 8 patients, the MERA team made recommendations to the treating team but these could not be discussed with the patient or SDM before the death or discharge of the patient. These patients were excluded from the analysis of effect and acceptability to patients/SDMs. Participant demographics are presented in Table 1.

Baseline patient perception and symptom data are provided in Appendix 2, Supplemental Table 1, available at www.cmajopen.ca/content/6/1/E87/suppl/DC1. Taken

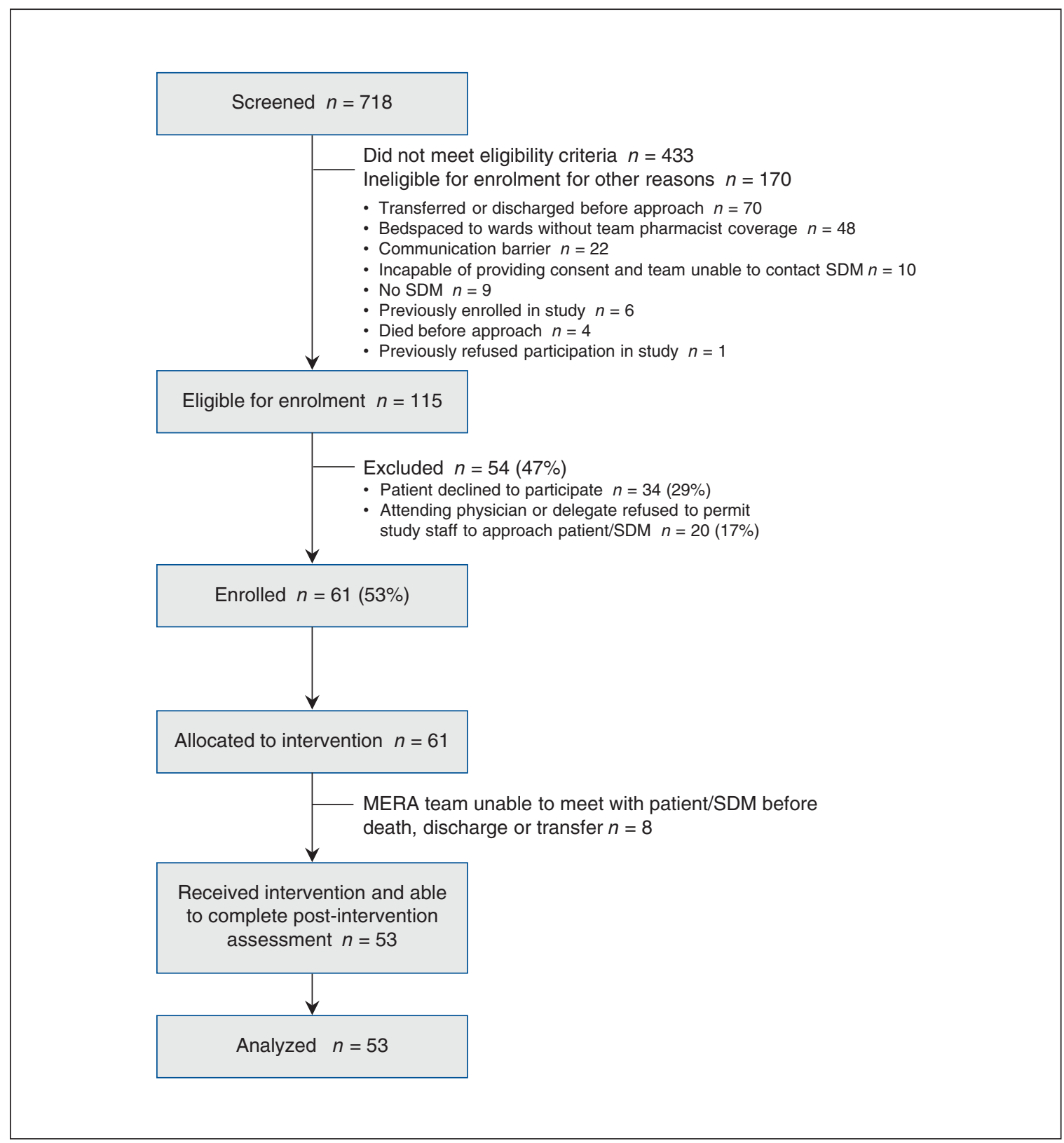

Figure 1: Patient enrolment CONSORT flow diagram. The term bedspaced means that the patient was admitted geographically to a ward other than the usual medical ward because of a lack of bed availability. MERA = Medication Rationalization. 


\begin{tabular}{|c|c|c|c|}
\hline Characteristic & $\begin{array}{l}\text { Intervention group } \\
\qquad(n=53)\end{array}$ & $\begin{array}{c}\text { Non-MERA } \\
\text { comparison group } \\
(n=51)\end{array}$ & $\begin{array}{c}p \text { value for difference } \\
\text { between intervention } \\
\text { and comparison } \\
\text { groups }\end{array}$ \\
\hline Age, yr, mean \pm SD & $79.6 \pm 11.7$ & $79.2 \pm 13.4$ & $0.9^{*}$ \\
\hline Mean hospital length of stay, mean \pm SD & $10.6 \pm 8.4$ & $7.7 \pm 17.0$ & $0.3^{*}$ \\
\hline \multicolumn{4}{|l|}{ Admission diagnosis, $n(\%)$} \\
\hline Cancer & $10(19)$ & $10(20)$ & \\
\hline Cardiovascular (e.g., stroke, myocardial infarction) & $6(11)$ & $9(18)$ & \\
\hline Respiratory (e.g., COPD exacerbation, pneumonia) & $12(23)$ & $7(14)$ & \\
\hline Age $>80 \mathrm{yr}$ & $22(42)$ & $23(45)$ & \\
\hline Metastatic cancer & $20(38)$ & $21(41)$ & \\
\hline End-stage organ failure & $11(21)$ & $7(14)$ & \\
\hline $\begin{array}{l}\text { Medications at the time of enrolment (intervention group) } \\
\text { or day } 3 \text { of admission (comparison group), mean } \pm \text { SD }\end{array}$ & $13.3 \pm 6.1$ & $10.9 \pm 4.5$ & $0.03 \ddagger$ \\
\hline \multicolumn{4}{|l|}{ Clinical Frailty Score, $n(\%)$} \\
\hline $1-3$ & $21(40)$ & NA & \\
\hline $4-5$ & $18(35)$ & NA & \\
\hline $6-8$ & $13(25)$ & NA & \\
\hline
\end{tabular}

together, the BMQ scores indicate that participants generally believed that their medications were necessary (but this belief was not strong), and they did not have strong concerns about harm and overuse (a more detailed explanation is provided in Appendix 1, Supplement E). The scores from the PATD questionnaire indicated that participants generally felt that they were taking a large number of medications $(61 \%)$ and only 29 of the 53 patients included in the analysis (55\%) felt that their medications were necessary. There was a strong willingness to stop one or more medications (91\%) or take additional medications (68\%) if suggested by a physician. Participants were comfortable with the idea of a pharmacist stopping a medication, provided that their physician was informed $(75 \%)$, and there was a strong preference for a faceto-face encounter to follow up on any decision to stop a medication $(66 \%)$. Average patient symptom severity scores on the ESAS-r were in the low to moderate range (1.3-5.2), but each patient had an average of 2.1 symptom scores greater than 6 (severe).

The median duration of MERA meetings with the admitting team was 7 minutes (range $1-12 \mathrm{~min}$ ), and the MERA team recommended a total of 263 medication changes, affecting 51 of 53 (96\%) enrolled patients (Figure 2). Of the 201 recommendations to stop medications, the medical team accepted $176(88 \%)$ and the patient/SDM accepted 162, for a combined acceptance rate of $81 \%$. Sixty-one of $62(98 \%)$ recommendations to change doses/frequencies or add medications were accepted by both the medical team and the patient/SDM, for an overall recommendation acceptance rate of 223/263 (85\%). MERA recommendations resulted in the discontinuation of 162 medications, with a mean of 3.1 (standard deviation [SD] 2.6) per patient, dose changes for 48 medications (mean 0.9 [SD 1.5] per patient) and the addition of 13 medications (mean 0.2 [SD 0.5] per patient) (Table 2). The most common recommended discontinuations were vitamins/minerals, lipid-lowering agents, homeopathic/ herbal supplements, proton pump inhibitors and docusate (Table 3). These 5 medications/classes accounted for $55 \%$ of all recommended discontinuations. The medications added were opioids (3), mirtazapine (3), inhaled bronchodilators (2), non-opioid analgesics (2), metoclopramide (1), rivaroxaban (1) and paroxetine (1). 


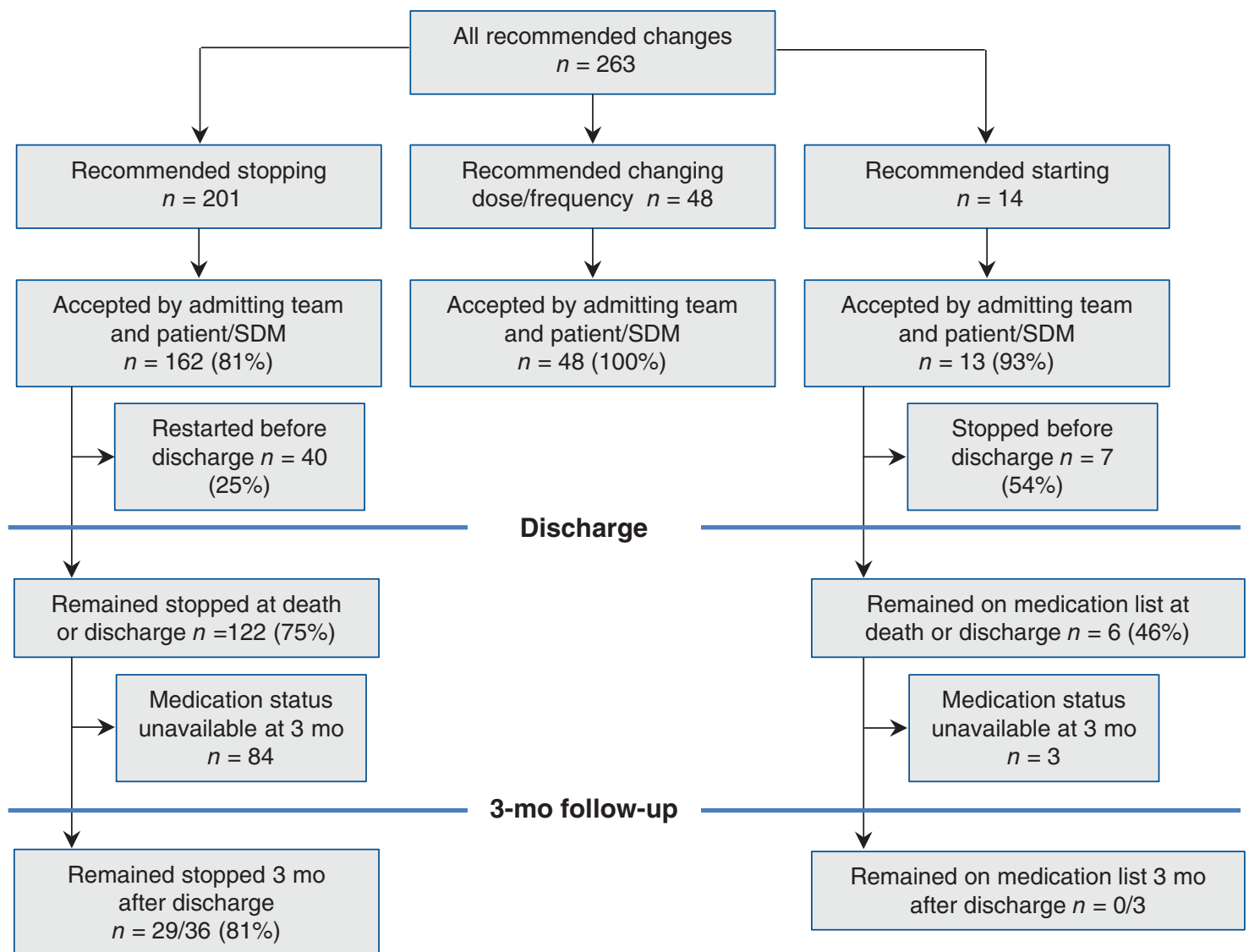

Figure 2: Flow chart of medication recommendations and changes.

Table 2: Differences in medication discontinuation among groups and subgroups

\begin{tabular}{|c|c|c|}
\hline Variable & $\begin{array}{l}\text { No. of medication } \\
\text { discontinuations, mean } \pm \text { SD }\end{array}$ & $p$ value for difference \\
\hline MERA intervention group & $3.1 \pm 2.6$ & $<0.001^{*}$ \\
\hline Non-MERA comparison group & $0.9 \pm 1.5$ & \\
\hline \multicolumn{3}{|l|}{ Within intervention group } \\
\hline Main inclusion criterion & & $0.6 \dagger$ \\
\hline Age $>80 \mathrm{yr}$ & $3.0 \pm 3.1$ & \\
\hline Metastatic cancer & $2.8 \pm 1.7$ & \\
\hline End-stage organ failure & $3.6 \pm 2.9$ & \\
\hline Role of palliative care & & $0.4 \dagger$ \\
\hline Followed by palliative care specialist & $4.0 \pm 2.8$ & \\
\hline Never followed by palliative care specialist & $2.8 \pm 2.3$ & \\
\hline $\begin{array}{l}\text { Palliative care consultation suggested by MERA team } \\
\text { but refused by admitting team or patient }\end{array}$ & $2.8 \pm 3.3$ & \\
\hline
\end{tabular}


Table 3: Most common medications recommended to be stopped by the MERA team

\begin{tabular}{|c|c|c|}
\hline MERA medication class & $\begin{array}{l}\text { No. of times MERA team recommended } \\
\text { discontinuation (\% of all recommended } \\
\text { discontinuations), } n=201\end{array}$ & $\begin{array}{l}\text { No. of patients in whom medication class } \\
\text { was recommended to be stopped (\% of all } \\
\text { patients enrolled), } n=53\end{array}$ \\
\hline Lipid-lowering agents & $20(10)$ & $20(38)$ \\
\hline Homeopathic/herbal supplements & $14(7)$ & $6(11)$ \\
\hline Antiplatelet agents & $7(3)$ & $7(13)$ \\
\hline Benzodiazepines & $6(3)$ & $6(11)$ \\
\hline Bisphosphonates (oral) & $5(2)$ & $5(9)$ \\
\hline Dihydropyridine calcium-channel blockers & $5(2)$ & $5(9)$ \\
\hline Nonbenzodiazepine hypnotics & $4(2)$ & $4(8)$ \\
\hline Thiazide diuretics & $4(2)$ & $4(8)$ \\
\hline
\end{tabular}

Of the 162 medications that were stopped, 40 (25\%) were restarted during hospital admission or at the time of discharge (Figure 2). In a post-hoc analysis, we found that the likelihood of medications being restarted on discharge was not affected by whether or not a pharmacist was involved in the discharge medication reconciliation $\left(\chi^{2}=0.34, p=0.6\right.$, data not shown). Of the 122 medications that remained discontinued at the time of discharge, 102 were for patients discharged alive; we were able to assess the status of 36 medications (16 patients) at 3 months after discharge because both the patient and the medication were covered by the ODB program, and the patient neither died nor was transferred to a palliative care unit during the admission or the follow-up period. The ODB records revealed that 29/36 (81\%) remained discontinued. We could not assess the status of the remaining medications because the patient had died or been transferred to an inpatient palliative care unit ( 5 patients, 23 medications), or the medication or patient was not covered by this plan (41 medications), or the medication was for hospital use only and would not have been expected to be used after discharge (2 medications). Using ODB cost data and assuming that prescriptions required one refill in the 100 days after discharge, we found that the total direct cost of these stopped medications was $\$ 1508.47$, or $\$ 94.28$ per 100 patient-days. Of the 13 medications added, 6 were stopped before discharge. Six of these medications were prescribed on discharge ( 1 medication was taken by a patient who died during admission) and of these, 3 were taken by patients who either died or were transferred to a palliative care unit within 3 months after discharge; therefore, we could not assess the status of these medications. The remaining 3 prescriptions were not filled according to the ODB record.
The medication changes made in response to the MERA intervention were compared with medication changes made on the 2 non-MERA comparison CTUs for 51 consecutive patients admitted over the same study period who met our inclusion criteria (Table 1). There was no difference between the 2 groups in the number of medication discontinuations that would have been recommended by the MERA algorithm (3.7 v. $3.8, p=0.95)$, but significantly more of these medications were actually stopped in the intervention group (3.1 v. $0.9, p<0.001$; Table 2). Using a multivariable linear regression analysis including treatment group (MERA v. non-MERA comparison), age, sex, inclusion criterion and number of baseline medications, we found that both the treatment group $(p<0.001)$ and number of baseline medications $(p<0.001)$ were associated with the number of medications stopped. Within the MERA intervention group, the number of medications discontinued was not influenced by the main inclusion criterion or whether or not a palliative care team was previously involved in the patient's care (Table 2). In a multivariable linear regression analysis that included each of the domains of the BMQ, the total ESAS-r score, the number of "severe" symptoms $(>6)$ on the ESAS-r and the Clinical Frailty Score, only the BMQ-General domain was significantly associated with the number of medications discontinued ( $p=0.02$, data not shown).

We were able to administer a follow-up questionnaire to 41 patients or SDMs after the recommendations were discussed with them (Appendix 2, Supplemental Figure 1). A majority reported being comfortable with starting (11/14, $79 \%)$ and stopping $(33 / 38,87 \%)$ medications as recommended by the MERA team, and only a very small number found the experience stressful $(2 / 39,5 \%)$ or confusing $(4 / 39,11 \%)$. Thirty-seven of 40 respondents $(93 \%)$ 
reported being "glad" that the MERA team reviewed their medications.

We administered a follow-up survey to the members of the medical team who participated in the MERA meetings, obtaining 16 responses (response rate of $53 \%$ ). Respondents reported that medication rationalization was a good idea (100\%), that it was easy to discuss MERA recommendations with patients $(87 \%)$ and that "MERA meetings were a good use of my time" (94\%). No respondent felt that it was difficult to attend the MERA meetings, that the meetings were too long or that the MERA team's involvement negatively affected their own relationship with the patient or SDM.

\section{Interpretation}

In this single-centre study, we pilot tested an innovative interprofessional medication-focused intervention aimed at medication rationalization (MERA), including both deprescribing of harmful or nonbeneficial medications and addition of comfort medications for inpatients with a limited life expectancy because of serious illness, advanced comorbidities or frailty. We found that the MERA intervention met or exceeded all pilot objectives; it was feasible and possibly effective for reducing medication use and costs in both the short and long term; it was efficient and acceptable for the admitting team; and it was satisfactory to the patient and family. We also learned lessons to improve the scalability and effectiveness of MERA in a larger, multicentre study.

In our study population of elderly, frail or seriously ill inpatients, we found that virtually every patient was taking multiple medications that were either unnecessary or potentially harmful. Up to $40 \%$ of frail elderly patients are prescribed medications that are potentially inappropriate for them according to guidelines, ${ }^{13}$ and up to $30 \%$ of hospital admissions for patients over 75 years of age are medication related; a large proportion of these admissions are preventable. ${ }^{29}$ Deprescribing interventions delivered on medical wards can be effective, ${ }^{19}$ but often patients are discharged on the same, if not more, medications. ${ }^{30-32} \mathrm{We}$ previously found that even patients treated with a palliative intent in our institution received an average of 40 doses of non-comfort medications in the week before their death or transfer to a palliative care unit. ${ }^{4}$ Although we found only a modest reduction in direct medication costs in our population of patients nearing the end of life, other studies have shown the large potential financial costs of inappropriate prescription on a population scale,,$^{15,16}$ and medication costs are often partially borne by patients themselves.

Our participants were comfortable stopping medications if their medical team felt it was possible, and virtually all were grateful that the MERA team reviewed their medications. Previous deprescribing interventions have sometimes had little or no effect, ${ }^{33}$ and there are multiple factors that shape both prescriber ${ }^{34}$ and patient $t^{35}$ barriers to deprescribing including complexity and time limitations, an underappreciation of the scale of polypharmacy-related harms, the increasing intensity of medical care in general, the fear of precipitating an acute event, and the conceptual difficulty involved in balancing risks and benefits., ${ }^{3,13}$ Only $21 \%$ of the Choosing Wisely campaign's current recommendations refer to stopping specific medications. ${ }^{36}$ Physicians may also hesitate to label a medication as being of low value for a patient, ${ }^{36}$ especially when that medication may have been prescribed by another physician and the patient appears to be tolerating it well. ${ }^{13}$ Even patients who dislike taking medications may be upset by the implication that they are too sick or too close to death to gain any benefit from them..$^{35}$ The MERA intervention used an innovative, pharmacist-led approach that appeared to be reassuring to patients, SDMs and health care professionals alike. Notably, the effectiveness of the MERA approach was seen broadly, regardless of the patient's views about their medications, their symptom burden, their degree of frailty, their age or their diagnosis. The approach was also equally effective in patients already seen by a palliative care specialist, and the comparison with non-MERA CTUs suggests that MERA provides a benefit not seen in "routine" interprofessional care.

Although our limited follow-up data suggested that the effect of MERA was durable, there were a substantial number of medications restarted at discharge. These medications may have been restarted deliberately, or they may have been accidentally restarted because of poor communication at the time of medication reconciliation. Our Medication Reconciliation Program uses multiple sources of information, but our discharge forms are electronically prepopulated and can prompt providers to restart discontinued medications in error, as has been shown by Stockton and colleagues. ${ }^{37}$ To improve the effectiveness of MERA, rationalization and reconciliation will need to be better integrated. Garfinkel and Mangin tested a similar intervention in community-dwelling seniors (who do not experience transfers of care shortly after the intervention), and they reported that $81 \%$ of their discontinuations remained effective after a mean follow-up of 19 months. ${ }^{38}$

Strengths of this study include the collection of perspectives from multiple types of participants (patients, SDMs and members of the medical team) and data on multiple dimensions (e.g., symptom burden, function, medication changes, and views on medications and deprescribing) to study a novel, interdisciplinary intervention to address a common problem in the seriously ill and frail elderly.

\section{Limitations}

Limitations of this study include the fact that it was a singlecentre, nonrandomized pilot study involving a dedicated, independent team, which precludes broad interpretation of the effectiveness of the MERA intervention. Our follow-up data were limited to medications covered by the ODB program, without quality of life measures. The enrolment rate of $53 \%$ is typical for studies of palliative-relevant topics, ${ }^{39}$ but it raises concerns about a selection bias as patients or SDMs who enrolled in this study may have been particularly keen to stop their medications, although the BMQ and PATD results suggest that this was not the case. However, participants in our comparison group were identified retrospectively without being enrolled and randomly assigned; they may not have accepted MERA recommendations as readily as our enrolled 
patients did. Admitting team members who did not complete the follow-up survey may not have shared the enthusiasm for MERA shown by those who did respond. Our cost data included only the costs of the medications that were stopped; the cost of the MERA team itself (e.g., the time taken to prepare reports) was not captured. Finally, an intervention of this nature involves medical, social and ethical considerations that may not be captured by quantitative methods; our qualitative results will be presented separately.

\section{Conclusion}

We found that the MERA intervention was feasible, acceptable, efficient and possibly effective for changing medication use among seriously ill and/or frail elderly inpatients in a single-centre pilot study. Future studies will explore the possibility of automating the MERA approach to improve scalability, better integrating MERA with medication reconciliation, and testing this approach in other care settings.

\section{References}

1. Kuijpers MA, van Marum RJ, Egberts AC, et al. Relationship between polypharmacy and underprescribing. Br 7 Clin Pharmacol 2008;65:130-3.

2. Linton A, Garber M, Fagan NK, et al. Examination of multiple medication use among TRICARE beneficiaries aged 65 years and older. 7 Manag Care Pharm 2007;13:155-62.

3. Farrell B, Shamji S, Monahan A, et al. Clinical vignettes to help you deprescribe medications in elderly patients: introduction to the polypharmacy case series. Can Fam Physician 2013;59:1257-8.

4. Ma G, Downar J. Noncomfort medication use in acute care inpatients comanaged by palliative care specialists near the end of life: a cohort study. Am 7 Hosp Palliat Care 2013;31:812-9.

5. Downar J, Rodin D, Barua R, et al. Rapid response teams, do not resuscitate orders, and potential opportunities to improve end-of-life care: a multicentre retrospective study. 7 Crit Care 2013;28:498-503.

6. American Geriatrics Society 2012 Beers Criteria Update Expert Panel. American Geriatrics Society updated Beers Criteria for potentially inappropriate medication use in older adults. 7 Am Geriatr Soc 2012;60:616-31.

7. O'Connor MN, Gallagher P, O'Mahony D. Inappropriate prescribing criteria, detection and prevention. Drugs Aging 2012;29:437-52.

8. Gallagher P, Ryan C, Byrne S, et al. STOPP (Screening Tool of Older Person's Prescriptions) and START (Screening Tool to Alert doctors to Right Treatment). Consensus validation. Int 7 Clin Pharmacol Ther 2008;46:72-83.

9. Currow DC, Stevenson JP, Abernethy AP, et al. Prescribing in palliative care as death approaches. 7 Am Geriatr Soc 2007;55:590-5.

10. Riechelmann RP, Krzyzanowska MK, Zimmermann C. Futile medication use in terminally ill cancer patients. Support Care Cancer 2009;17:745-8.

11. Fede A, Miranda M, Antonangelo D, et al. Use of unnecessary medications by patients with advanced cancer: cross-sectional survey. Support Care Cancer 2011; 19:1313-8.

12. Néron A. Table 31.1: Classification of drugs according to medical necessity at end of life. In: Care beyond cure: management of pain and other symptoms, 4th edition. Montréal: Association des pharmaciens des établissements de santé du Québec, and Boucherville (QC): Sandoz; 2009.

13. Scott IA, Anderson K, Freeman CR, et al. First do no harm: a real need to deprescribe in older patients. Med f Aust 2014;201:390-2.

14. Berterame S, Erthal J, Thomas J, et al. Use of and barriers to access to opioid analgesics: a worldwide, regional, and national study. Lancet 2016;387:1644-56.

15. Pellegrin KL, Krenk L, Oakes SJ, et al. Reductions in medication-related hospitalizations in older adults with medication management by hospital and community pharmacists: a quasi-experimental study. 7 Am Geriatr Soc 2017;65: 212-9.

16. Gillespie U, Alassaad A, Henrohn D, et al. A comprehensive pharmacist intervention to reduce morbidity in patients 80 years or older: a randomized controlled trial. Arch Intern Med 2009;169:894-900.

17. Kaboli PJ, Hoth AB, McClimon BJ, et al. Clinical pharmacists and inpatient medical care: a systematic review. Arch Intern Med 2006;166:955-64.

18. Potter K, Flicker L, Page A, et al. Deprescribing in frail older people: a randomised controlled trial. PLoS One 2016;11:e0149984.

19. McKean M, Pillans P, Scott IA. A medication review and deprescribing method for hospitalised older patients receiving multiple medications. Intern Med 7 2016; 46:35-42.

20. Tjia J, Velten SJ, Parsons C, et al. Studies to reduce unnecessary medication use in frail older adults: a systematic review. Drugs Aging 2013;30:285-307.
21. Dellit TH, Owens RC, McGowan JE Jr, et al. Infectious Diseases Society of America and the Society for Healthcare Epidemiology of America guidelines for developing an institutional program to enhance antimicrobial stewardship. Clin Infect Dis 2007;44:159-77.

22. Medication reconciliation (Medrec). Edmonton and Ottawa: Canadian Patient Safety Institute. Available: http://www.patientsafetyinstitute.ca/en/Topic/ Pages/medication-reconciliation-(med-rec).aspx (accessed 2018 Jan. 24).

23. Mueller SK, Sponsler KC, Kripalani S, et al. Hospital-based medication reconciliation practices: a systematic review. Arch Intern Med 2012;172:1057-69.

24. Kwan JL, Lo L, Sampson M, et al. Medication reconciliation during transitions of care as a patient safety strategy: a systematic review. Ann Intern Med 2013; 158:397-403.

25. Heyland DK, Dodek P, Rocker G, et al. What matters most in end-of-life care: perceptions of seriously ill patients and their family members. CMAf 2006;174:627-33.

26. Reeve E, Shakib S, Hendrix I, et al. Development and validation of the patients' attitudes towards deprescribing (PATD) questionnaire. Int 7 Clin Pharm 2013;35:51-6.

27. Horne R, Weinman J, Hankins M. The beliefs about medicines questionnaire: the development and evaluation of a new method for assessing the cognitive representation of medication. Psychology \& Health 1999;14:1-24.

28. Bruera E, Kuehn N, Miller MJ, et al. The Edmonton Symptom Assessment System (ESAS): a simple method for the assessment of palliative care patients. 7 Palliat Care 1991;7:6-9.

29. Runciman WB, Roughead EE, Semple SJ, et al. Adverse drug events and medication errors in Australia. Int 7 Qual Health Care 2003;15(Suppl 1):i49-59.

30. Hubbard RE, Peel NM, Scott IA, et al. Polypharmacy among inpatients aged 70 years or older in Australia. Med 7 Aust 2015;202:373-7.

31. Betteridge TM, Frampton CM, Jardine DL. Polypharmacy - we make it worse! A cross-sectional study from an acute admissions unit. Intern Med 7 2012;42:208-11.

32. Poudel A, Peel NM, Nissen L, et al. Potentially inappropriate prescribing in older patients discharged from acute care hospitals to residential aged care facilities. Ann Pharmacother 2014;48:1425-33

33. Williams ME, Pulliam CC, Hunter R, et al. The short-term effect of interdisciplinary medication review on function and cost in ambulatory elderly people. 7 Am Geriatr Soc 2004;52:93-8.

34. Anderson K, Stowasser D, Freeman C, et al. Prescriber barriers and enablers to minimising potentially inappropriate medications in adults: a systematic review and thematic synthesis. BMF Open 2014;4:e006544.

35. Reeve E, To J, Hendrix I, et al. Patient barriers to and enablers of deprescribing: a systematic review. Drugs Aging 2013;30:793-807.

36. Morden NE, Colla CH, Sequist TD, et al. Choosing Wisely - the politics and economics of labeling low-value services. N Engl 7 Med 2014;370:589-92.

37. Stockton KR, Wickham ME, Lai S, et al. Incidence of clinically relevant medication errors in the era of electronically prepopulated medication reconciliation forms: a retrospective chart review. CMAJ Open 2017;5:E345-53.

38. Garfinkel D, Mangin D. Feasibility study of a systematic approach for discontinuation of multiple medications in older adults: addressing polypharmacy. Arch Intern Med 2010;170:1648-54.

39. Heyland DK, Barwich D, Pichora D, et al. Failure to engage hospitalized elderly patients and their families in advance care planning. 7 AMA Intern Med 2013;173:778-87.

Affiliations: Departments of Pharmacy (Whitty, Porter, Battu, Bhatt) and Medicine (Koo, R. Wu, P.E. Wu, Bogach, Downar) and Centre for Innovation in Complex Care (Delicaet), University Health Network; Centre for Addiction and Mental Health (Kalocsai), Toronto, Ont.

Contributors: Rachel Whitty, Sandra Porter, Kiran Battu and James Downar conceived and designed the study. Rachel Whitty, Sandra Porter, Kiran Battu, Pranjal Bhatt, Ellen Koo, Csilla Kalocsai and James Downar collected the data. All authors were involved in data analysis and interpretation. James Downar, Rachel Whitty, Sandra Porter, Kiran Battu and Peter $\mathrm{Wu}$ drafted the manuscript. All authors revised the manuscript, approved the final version for publication and agreed to be accountable for all aspects of the work.

Acknowledgments: This study was funded by a Catalyst Grant (CAT 2014-29) from the Canadian Frailty Network (a National Centre of Excellence), and additional funding was provided by the Toronto General and Western Hospital Foundation. The authors thank the University Health Network Pharmacy Department for contributing in-kind support to ensure the success of this project. None of the funders or in-kind contributors had any role in the design or interpretation of the study or in the preparation of the manuscript.

Supplemental information: For reviewer comments and the original submission of this manuscript, please see www.cmajopen.ca/content/6/1/ E87/suppl/DC1. 